\title{
Hajlort og -tcender \\ - fundet i stort antal under moleret på Mors
}



Af Henrik Madsen, Moler Museet

Fossile hajtænder er forholdsvis almindelige at finde i geologiske aflejringer rundt om i Verden. På nogle danske lokaliteter, som $\mathrm{fx}$ ved Faxe, Ølst/Hinge og Trelde Næs er fund af hajtænder ikke ualmindelige. Denne artikel fortæller bl.a. om fund af mange hajtænder i et specielt lag i Stolleklint Ler ved Sundby strand på Mors.

\section{Lokaliteten}

Øst for den gamle molergrav ved Sundby på Mors er der en strækning på ca. $600 \mathrm{~m}$, hvor terrænet på op til $80 \mathrm{~m}$ fra kysten, synker med jævne mellemrum. I 70'erne måtte man op over en bakke for at komme ned til stranden på stedet, som ses på fotoet ovenfor. Det er undergrundens beskaffenhed og kystklintens erosion, som er årsagen. Det ler, der synker inde i terrænet, presser lerlagene op ude på stranden, ofte op til $10 \mathrm{~m}$ fra klintens basis. Toppen af leret i udskridningerne tilhører de nederste lag af Fur Formationen og består af sedimenttypen diatomit, bedre kendt som moler. Disse nederste lag indeholder, ud over fossilt træ, ikke særligt mange makrofossiler. Stolleklintleret, der her findes på stranden, er lidt ældre end Fur Formationen og tilhører Ølst Formationen. Under Ølst Formationen ligger Holmehus Formationen.
Holmehus-ler

Typelokaliteten for Holmehus-leret ligger ved Røjle Klint på Fyn. Oven for Røjle Klint lå dyrlægens gård, som har givet navn til leret. Allerede i 1918 nævnte O.B. Bøggild, at der var en forekomst af plastisk ler

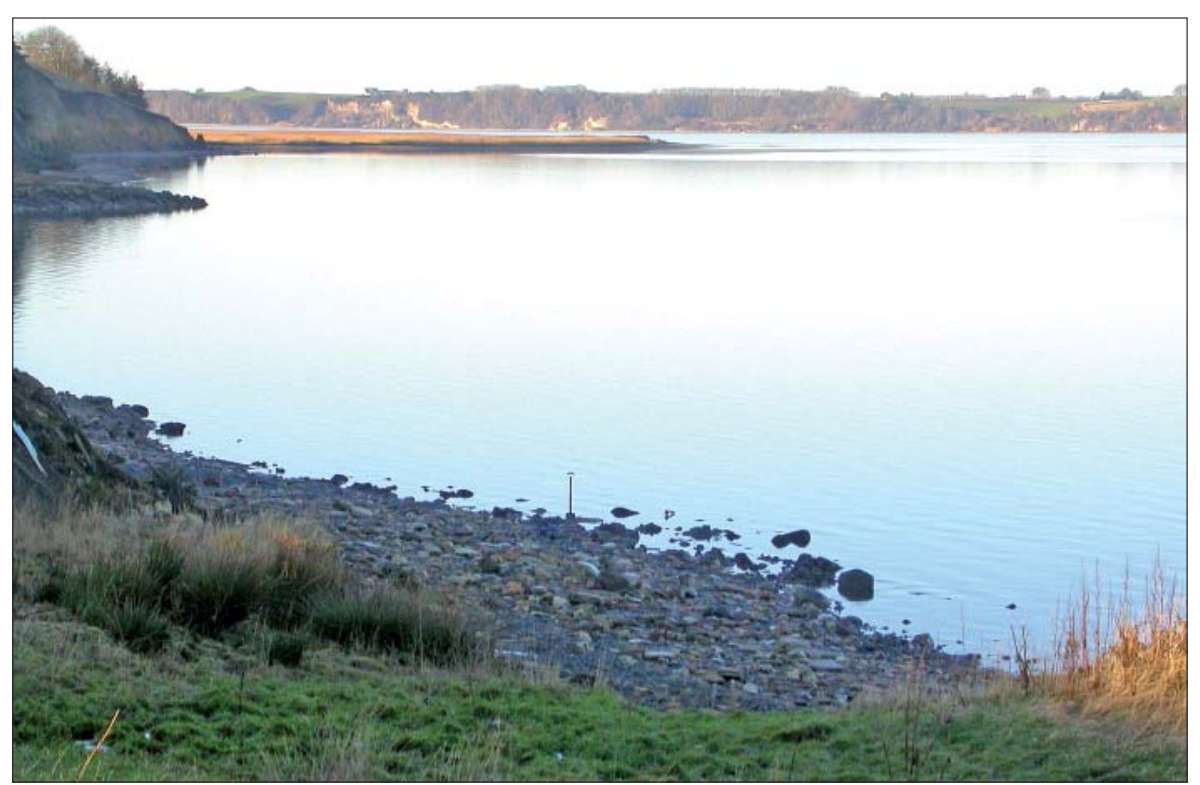

Udsigten mod vest over Sundby Stengrund til Ås i Thy. I vandkanten, midt på fotoet, ses en spade, hvor Sundby-laget blev fundet. (Foto: Forfatteren) 


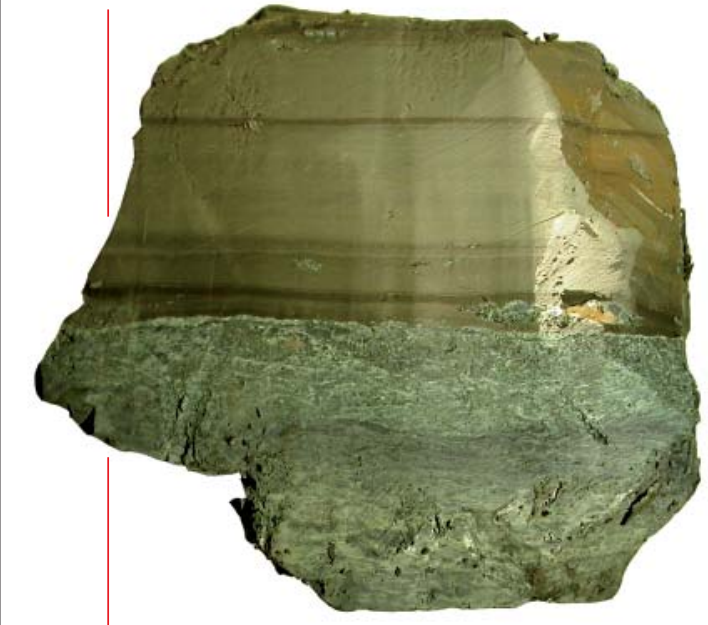

Fotoet viser øverst Stolleklint-leret liggende direkte på Holmehus-leret. Det ses tydeligt, at Stolleklint-leret er fint lamineret, hvorimod Holmehus-leret er forstyrret af gravegange. Grcenselaget markerer starten på den mest markante globale opvarmning de sidste 55 mio. år. (Foto: Forfatteren)

ved Holmehus, som, han formodede, var ældre end den kendte plastiske ler af eocæn alder. I 1985 publicerede Claus Heilmann Clausen m.fl. "Lithostratigraphy and depositional environments in the Upper Paleocene and Eocene of Denmark", hvor bl.a. Holmehus Formationen og Ølst Formationen defineres som nye formationer. Alderen på den øverste del af Holmehus Formationen er ca. 57,5 mio. år, og den ligger i tidsperioden Øvre Paleocæn. Lerets farve er grønlig og blålig og består af meget fine lerpartikler. Sedimentationshastigheden har været meget lav, hvilket har bevirket, at havvandets ilt kunne nedbryde de organiske rester af dyr

Figuren viser placeringen af de forskellige formationer, der omtales i artiklen. Overgangen mellem Holmehusog Stolleklint-leret er stadig ikke klarlagt. Østerrendeleret, som ligger mellem Holmehusleret og Stolleklint-leret, kendes fra boring ved Storebcelt, og findes ikke ved Sundby. Sundbylaget er placeret i eller ncer toppen af Stolleklint-leret. Tallene er udvalgte askelag. (Grafik: UVH og forfatteren modificeret efter Claus Heilmann Clausen)

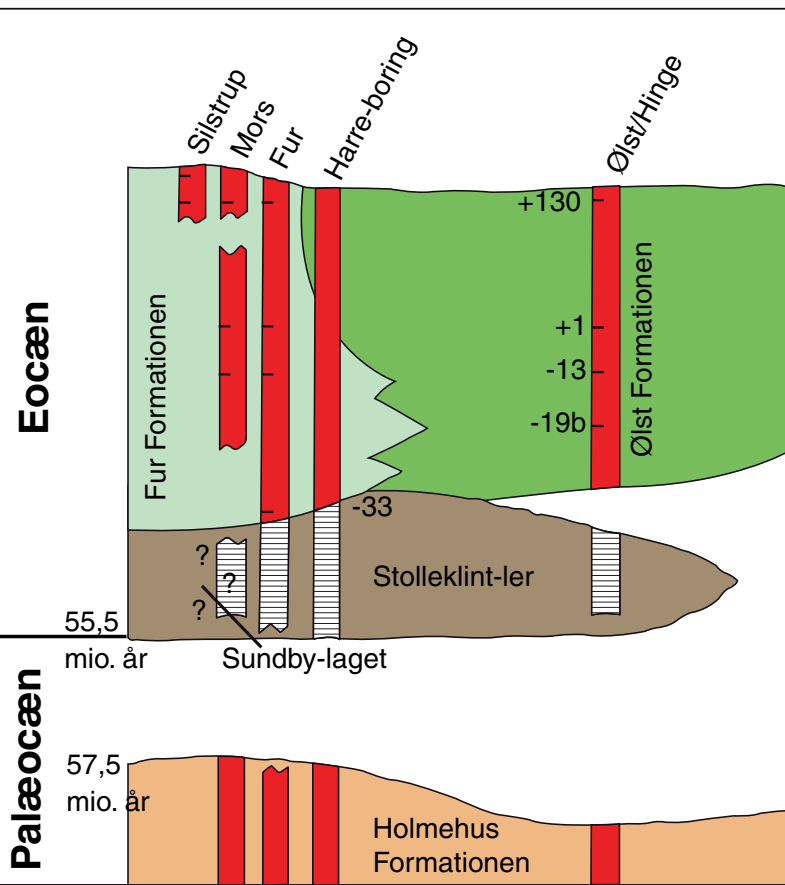

og planter, som havnede på bunden af havet. Af denne grund findes der ikke mange fossiler i dette ler. Vanddybden menes at havde været over $300 \mathrm{~m}$

\section{Stolleklint Ler}

Ved Stolleklint, Ølst/Hinge lergrave og ved Sundby Strand kan man, som de eneste steder, se Stolleklint-ler. Leret, der ligger lige under moleret, er den øverste del af Ølst Formationen. Dette ler er afsat i et totalt iltfrit indhav med en vanddybde på godt 100 m. Der blev afsat op til 14 m Stolleklintler, og det indeholder meget organisk stof. I de øverste lag af Stolleklint-leret er der



Øverst ses Stolleklint-leret, der adskilles af det lyse Sundby-lag, som indeholder mange fossiler. De nederste grønlige lag på fotoet er breccieret Stolleklint-ler. (Foto: Forfatteren)

et forkislet lag, der i daglig tale kaldes for "skifer". Slamsten er nok en mere rigtig betegnelse, da der ikke er tale om ægte skifer. Denne slamsten er rig på makrofossiler, og 
forfatteren har indsamlet den største samling overhovedet af dette lag. Heriblandt en del Danekræ. Jeg vil her kort nævne Danmarks første reje og Verdens ældste dagsommerfugl samt flere nye arter af fisk og insekter.

I disse øverste lag er der kun fundet ganske få hajtænder. Der er bred enighed om, at grænsen mellem tidsperioderne Paleocæn og Eocæn er ved basis af Stolleklint-leret. På denne grænse startede en ret pludselig global opvarmning. Gennemsnitstemperaturen steg ca. 5 grader i løbet af knap 10.000 år.

\section{Fund af "Terrazzo-laget"?}

Tilbage i 80'erne blev der fundet nogle flade konkretioner ved Sundby Strand af Claus Heilmann Clausen. Disse var ikke kalkholdige, men bestod af dolomit med mange ovale fosfatknolde. Dette karakteristiske udseende gav disse konkretioner navnet “Terrazzo-gulv”. Det var den første leder af Moler Museet, Bent Søe Mikkelsen, der i 1990 præsenterede mig for sit fund, som indeholdt en hajtand. Siden da har jeg jævnligt på ture til Sundby Strand søgt efter disse sjældne lag.

Det var dog først i december 2008, hvor det var meget lavvandet, at det muligvis lykkedes mig at finde laget, som befandt sig i sedimentet. Det var ikke et fuldstændigt hærdet lag, der fandtes mellem lerlagene, men det mindede om dette lag pga. de
Ncerbillede af

Sundby-laget.

Der ses flere af de brune koprolitter. Det skinnende er pyrit, og de grønlige korn er glaukonit. De mørke pletter på fotoet er rester af meget pyritholdigt, uforkislet trce. Det hele er kittet sammen. Billedudsnittet er 2,5 cm i højden. (Foto: Forfatteren)

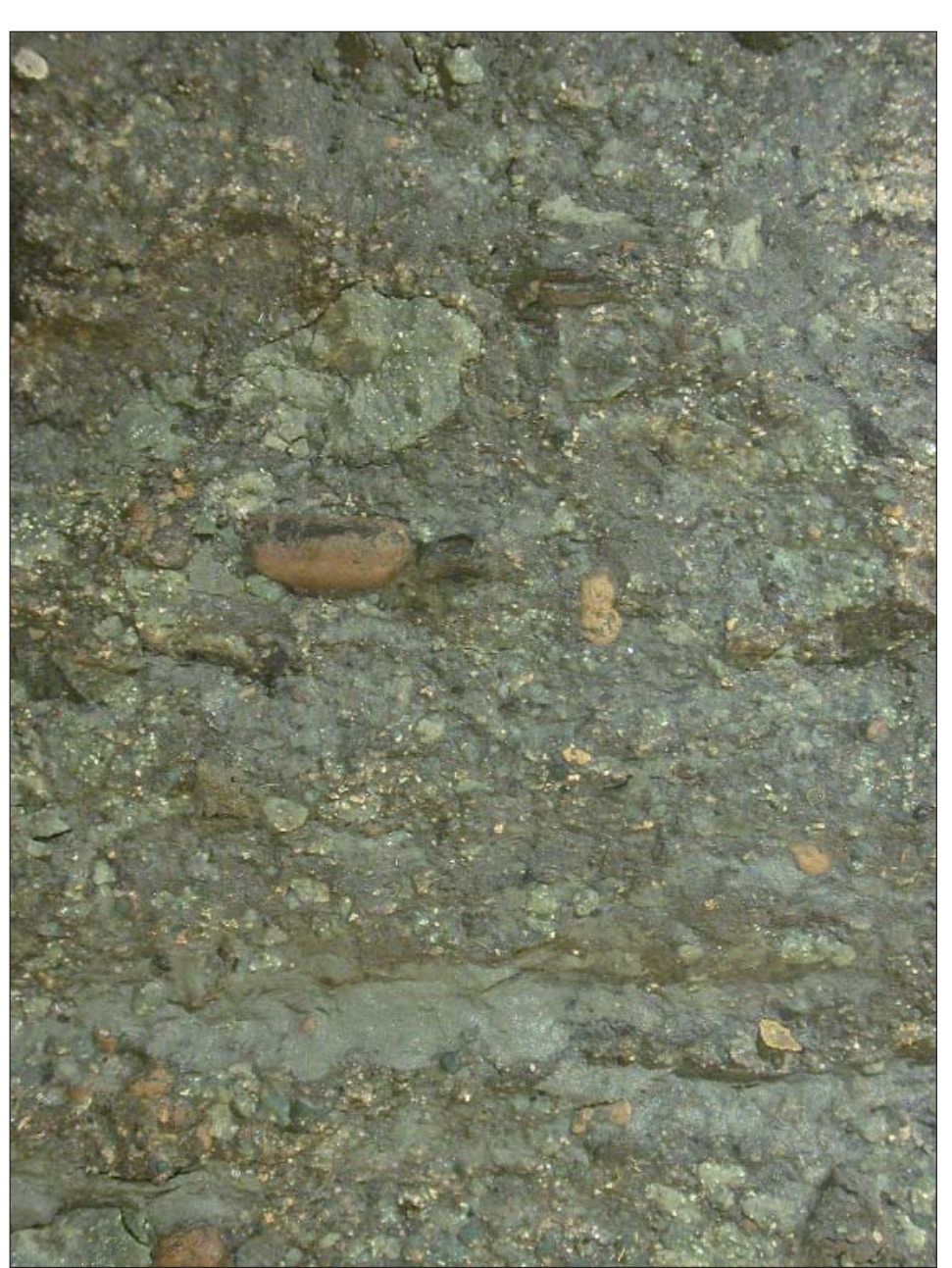


mange, typisk 0,5 -1 cm aflange, brunlige fosfatknolde.

De øvrige mineraler, som var til stede, fandtes i begge lag. Lagserien var på dette sted stærkt deformeret som følge af istidsforstyrrelser. Dette lag ses ikke på andre lokaliteter, så derfor vil jeg kalde laget for Sundby-laget, når det omtales i denne artikel. Sundby-laget var ikke gennemgående og var kun på et enkelt sted i et par meters længde. I forbindelse med laget var der i samme længde et stykke træ, som ikke var forkislet, men i mange brudstykker. Tilsyneladende er der en sammenhæng mellem træet og Sundby-laget, for laget kunne ikke følges i leret, som var i nærheden. Muligvis er de forskellige fossiler aflejret i læ for havstrøm af træstykket.

Der blev hjemtaget ca. $100 \mathrm{~kg}$ materiale. For at få hele Sundby-laget med blev der også opgravet noget af Stolleklint-leret, så det var kun få kg af det samlede materiale, der bestod af selve Sundby-laget. De $100 \mathrm{~kg}$ blev gennemtørret og herefter tilsat vand, så det var mættet. På denne måde opslemmedes lermaterialet og blev herefter sigtet gennem en almindelig køkkensigte. Det finkornede ler blev herefter udvasket, hvilket reducerede mængden af materiale betydeligt. Tilbage var de ikke vandopløselige mineraler og fossiler. Hajtænderne var der som forventet, men antallet overraskede, for det viste sig, at der var 680 hajtænder i det opslemmede materiale.

\section{Hajtænder og ryghvirvler}

De fleste hajtænder var i stykker, kun $10 \%$ af tænderne var hele. Rødderne var itu eller helt væk på mange, og i flere tilfælde var kronen splintret på langs. Denne bevaringskvalitet er dog typisk på mange lokaliteter i både ind- og udland, hvor der findes hajt-

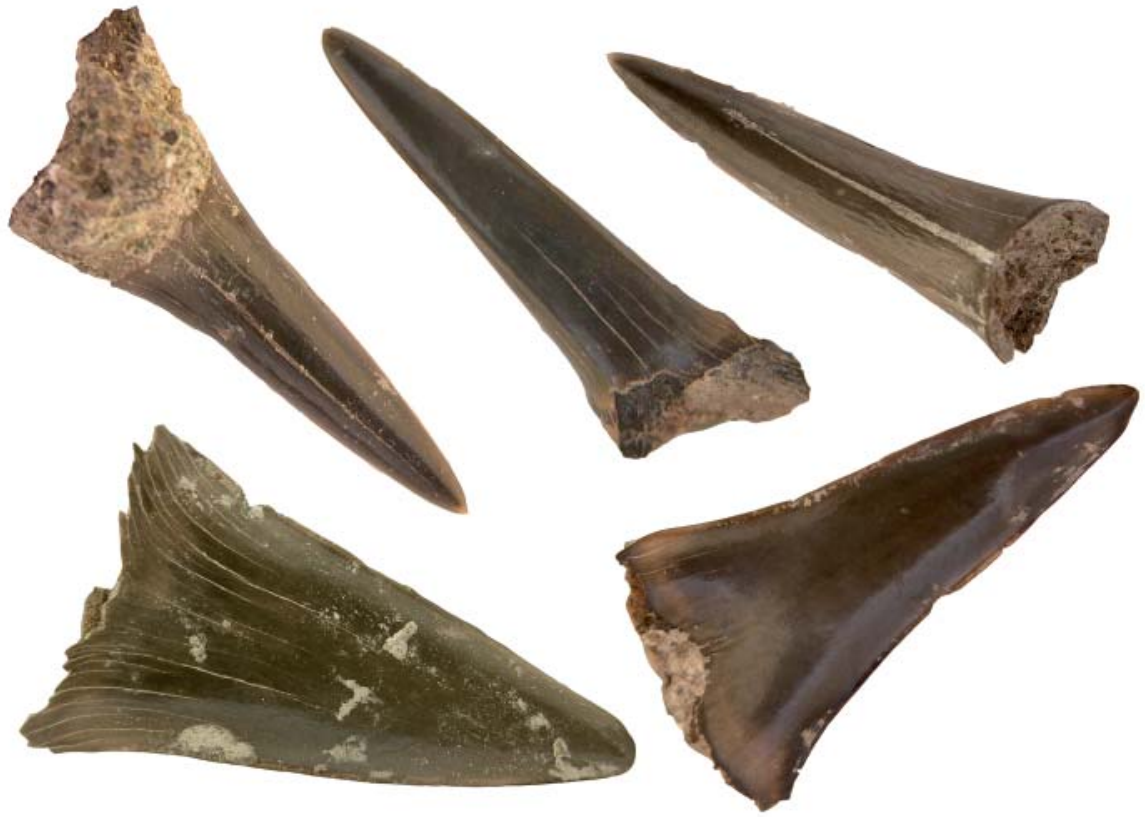

De største tcender fundet i Sundby-laget. Lœngde 1,7 cm. Det er de 2 mest almindelige arter. Sandhajerne Striatolamia striata og Carchais sp. (Foto: Forfatteren)

ænder. Der var 8-10 forskellige hajarter og 5 af de identificerede arter, Dragefinnehajen - Dalatias sp., Pighajen - Squalus sp., Gråhajerne - Abdounia sp. og Galeorhinus sp., kendes ikke fra de øverste lag i Stolleklintleret. De hyppigst fundne tænder fra Sandhajerne Striatolamia striata og Carcharias sp. er også de mest kendte arter i moleret.

Der blev desuden fundet enkelte tænder fra Sandhajen Palaeohypotodus rutoti, som også er kendt fra moleret. Det er dog meget sjældent at finde hajtænder i Stolleklint-leret og moleret. Ryghvirvler fra hajer blev der fundet 3 af, hvilket er ret typisk i forhold til antallet af fundne tænder. Grunden til, at der ikke er så mange hajhvirvler, er, at hajer er bruskfisk, og brusk forgår som noget af det første under forsteningsprocessen. De dele, der forstener, er nakkehvirvlerne, fordi hajers hvirvler med alderen gradvist forbener $\mathrm{i}$ nakken. Hajryghvirvler er svære at identificere, og de fundne hvirvler er ikke nærmere bestemt.

Der blev også fundet et enkelt fragment af en anden type bruskfisk. Fundet var en sekskantet lateral plade på $0,3 \mathrm{~cm}$ fra tandpladen hos en Ørnerokke - Myliobatis sp.

\section{Hajekskrementer}

På fundtidspunktet var jeg ikke klar over, at
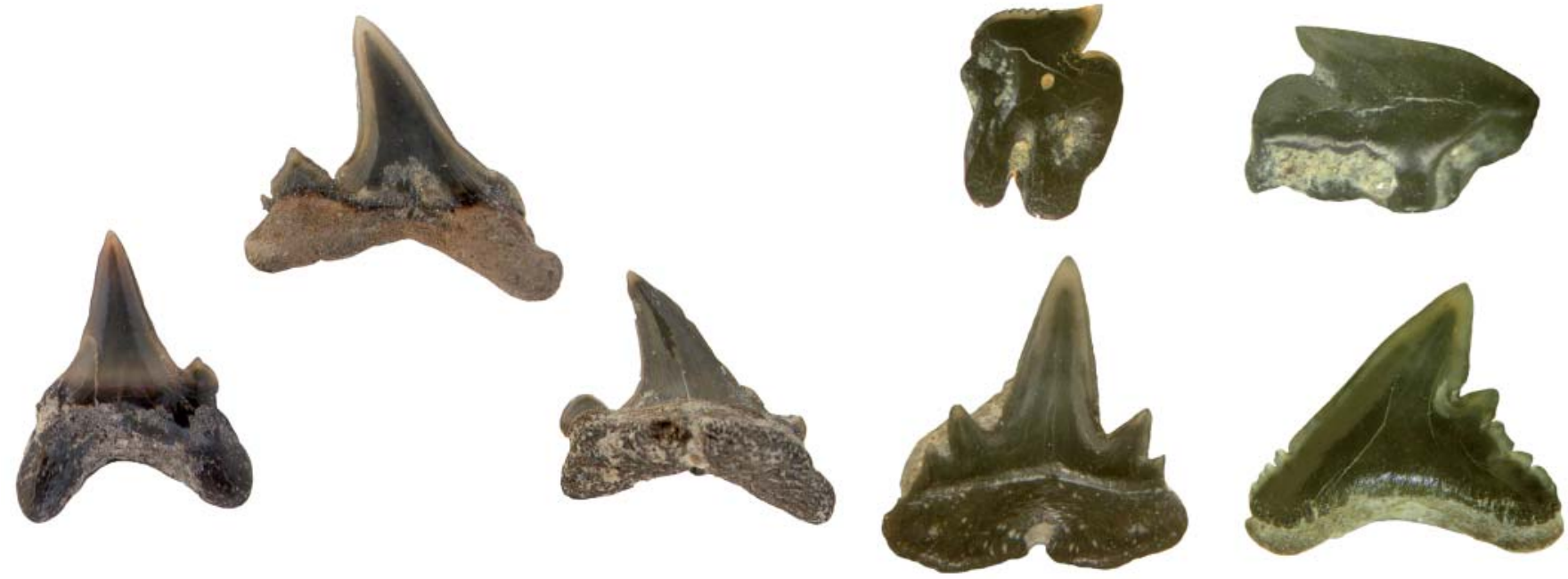

3 Velbevarede tender med roden bevaret. De er alle fra Sandhaj-familien. T.v. er det en Carcharias sp., og de 2 andre er Striatolamia striata. Størrelsen er 0,5 cm i højden. (Foto: Forfatteren)

Hajtcender fra 4 arter. Øverst Dragefinnehaj - Dalatias sp., ø.t.h. Pighajen - Squalus sp., n.t.v. Gråhajen - Abdounia sp., n.t.h. Gråhajen - Galeorhinus sp.. Mindste tand er $3 \mathrm{~mm}$ i højden. (Foto: Forfatteren) 



Ryghvirvel fra uidentificeret lille haj. Diameter: 0,4 cm. (Foto: Forfatteren)

det faktisk var koprolitter, der her var tale om. Dette blev jeg gjort opmærksom på af geolog Claus Heilmann Clausen, Geologisk Institut i Århus. Under en samtale om stratigrafien ved Sundby nævnte han, at det kunne være fiskeekskrementer. Et nærmere kig på fosfatkonkretionerne/koprolitterne viste, at der var flere, som var tydeligt spiralsnoede, hvilket er karakteristisk for hajers ekskrementer. Den spiralsnoede facon skyldes hajers tarmsystem. Den er kort, men snoet, så føden bedre kan optages.

Desuden indeholdt flere koprolitter ryghvirvler og knogler fra små benfisk.

\section{Benfisk}

Hos de fleste eksemplarer af tænder og ryghvirvler er bevaringskvaliteten helt i top, men rigtigt mange af tænderne og ryghvirvlerne var mere eller mindre omsluttet af dolomit. Hvirvlernes størrelse er fra $0,1 \mathrm{~cm}$ op til 1,0 cm i diameter. Tændernes størrelse er i de fleste tilfælde 0,2 - 0,5 cm i højden. Det største eksemplar, som ses på fotoet ovenover, er bevaret anderledes end de øvrige tænder. Tanden har en bred krone med forstærket emalje, hvorimod resten af tanden ikke har emaljen bevaret. Der er i alt fundet 360 ryghvirvler fra benfisk og 152 tænder. Mange af de fundne hvirvler og tænder tilhører makrel-, lakse- og havaborre-familien. Der blev også fundet nogle få dele af knuse-


Koprolitter fra hajer findes i stort antal i Sundby-laget. Største eksemplar er $2 \mathrm{~cm}$ i langden. (Foto: Forfatteren)

tandplader. Desuden var der et utal af knoglefragmenter fra uidentificerede benfisk.

\section{Knogler fra krybdyr og fugl}

Et af de mest overraskende fund var ryghvirvler fra havslanger, Palaeophis sp. Der blev fundet 5 slangeryghvirvler. De ældste kendte slanger er fundet i Øvre Kridt. I Danmark er der tidligere fundet fossile dele af havslanger i moleret og i det plastiske ler i Hinge lergrav. Det drejer sig dog om enkelt fund i begge tilfælde. Det er dermed den ældste fossile slange i Danmark. Et foto af ryghvirvlen fra Sundby blev lagt på www. vestjyskstenklub.dk, og her blev den spottet af geolog Gilles Cuny på Geologisk Museum i Kbh. Han vurderede, at slangehvirvlen skulle indstilles som danekræ, da det er den ældste fossile repræsentant for havslanger i Danmark.

Den fundne fugleknogle var et fragment, og kan ikke bestemmes nærmere. Der blev også fundet enkelte fragmenter af skildpaddeknogler i Sundby-laget. Se artikel om fossile skildpadder i GeologiskNyt 2008/3.

\section{Mineralerne i lagene}

Der var en del pyrit i lagene samt barytkry-
Ryghvirvler fra 3 forskellige arter benfisk. Den mindste hvirvel er 3 mm i diameter. (Foto: Forfatteren)


Tcender fra 5 forskellige benfiskearter. Den mindste tand på fotoet er $3 \mathrm{~mm}$ i højden. (Foto: Forfatteren)
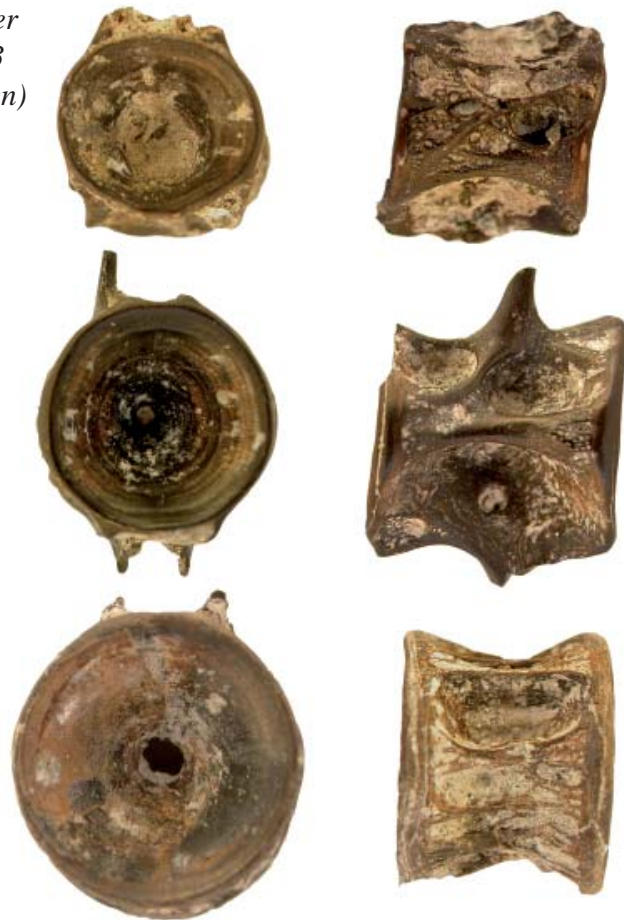
staller i stort antal. Det stammede fra konkretioner, som dog ikke i nogle tilfælde var hele. Desuden var der små hærdede sten af dolomit på op til $2 \mathrm{~cm}$ i diameter. Muligvis fordi laget har været mere sammenhængende på et tidspunkt. Mange af fossilerne var helt eller delvist omsluttet af denne bjergart. Både i leret og i dolomitstenene var der en del korn af glaukonit samt glimmerflager og kvartskorn i millimeter-størrelse.

Det stærkt pyritiserede træ, som alle disse fossiler lå i forbindelse med, kan ikke bestemmes, pga. den dårlige bevaring. Der blev også fundet 2 identiske frø fra en endnu ikke identificeret plante - om de har sammenhæng med træet kan ikke påvises.

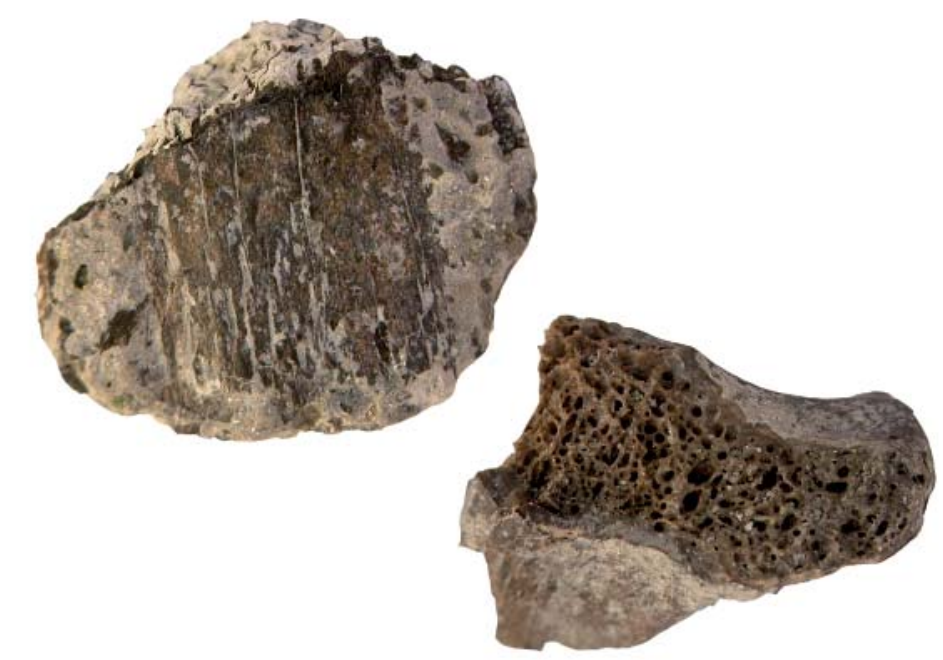

Knoglefragmenter fra skildpadde. Størrelse 1,4 cm. (Foto: Forfatteren)


En del af pyritkonkretionerne, som blev fundet, havde mange spøjse former. Læengden på de største er $0,8 \mathrm{~cm}$. (Foto: Forfatteren)

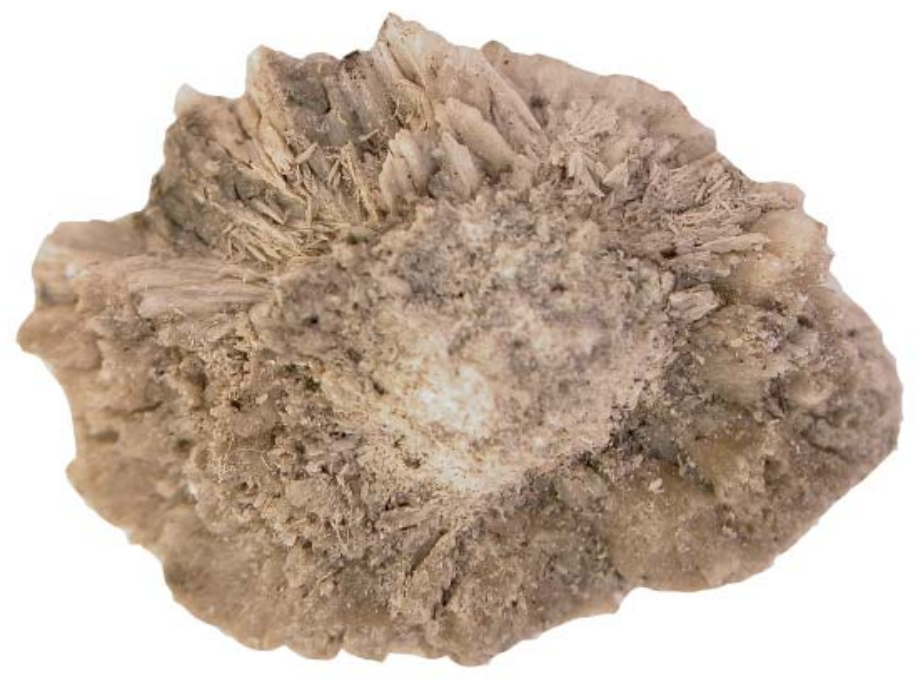

Baryt-konkretion. Størrelse: $2 \mathrm{~cm}$ ) (Foto: Forfatteren)


Ryghvirvel fra havslangen Palaeophis sp. Det er samme ryghvirvel set henholdsvis forfra, fra neden, samt fra siden. Med en for slanger karakteristisk kugleformet bagende som det ses til højre på nederste foto. Lcengde:1,1 cm. (Foto: Forfatteren) 